\title{
Breathlessness is associated with urinary incontinence in men: A community-based study
}

\author{
Fumi Hirayama', Andy H Lee ${ }^{1 *}$, Tetsuo Hiramatsu², Yoshimasa Tanikawa ${ }^{3}$
}

\begin{abstract}
Background: Urinary incontinence (UI) is a distressing problem for older people. To investigate the relationship between UI and respiratory symptoms among middle-aged and older men, a community-based study was conducted in Japan.

Methods: A convenience sample of 668 community-dwelling men aged 40 years or above was recruited from middle and southern Japan. The International Consultation on Incontinence Questionnaire-Short Form, the Medical Research Council's dyspnoea scale and the Australian Lung Foundation's Feeling Short of Breath scale, were administered by face-to-face interviews to ascertain their UI status and respiratory symptoms.

Results: The overall prevalence of UI was 7.6\%, with urge-type leakage (59\%) being most common among the 51 incontinent men. The presence of respiratory symptoms was significantly higher among incontinent men than those without the condition, especially for breathlessness ( $45 \%$ versus $30 \%, p=0.025$ ). The odds of UI for breathlessness was 2.11 (95\% confidence interval 1.10-4.06) after accounting for age, body mass index, smoking and alcohol drinking status of each individual.
\end{abstract}

Conclusions: The findings suggested a significant association between UI and breathlessness in middle-aged and older men.

\section{Background}

Urinary incontinence (UI) is a distressing condition and costly problem for older adults [1]. Established risk factors of UI are age, gender, obesity and smoking [2-4]. The prevalence of UI is also known to be higher among women with cystic fibrosis, $30.4 \%$ to $68 \%$ [5-7], than the general population of $10.4 \%$ to $23.9 \%$ [8-10]. Cough is the major cause of UI among 80 to $90 \%$ of females with cystic fibrosis, as frequent coughing may lead to imbalance within the muscles of abdomino-pelvic capsule [11]. The leakage of urine occurs when intra-vesical pressure exceeds urethral closure pressure in the absence of a detrusor contraction, or due to bladder neck hyper-mobility or poor urethral closure pressure [12]. In the literature, focus has been directed to females and coughing whereas investigation on incontinent males is scant [1]. A recent population-based study in the USA reported that men with asthma had twice the odds of leakage, especially for White men [13]. The purpose of this study is to ascertain the relationship

\footnotetext{
* Correspondence: Andy.Lee@curtin.edu.au

${ }^{1}$ School of Public Health, Curtin Health Innovation Research Institute, Curtin University of Technology, Perth, WA, Australia
}

between UI and respiratory symptoms in middle-aged and older community-dwelling men. The finding should be beneficial for the prevention and treatment of this irritating condition.

\section{Methods \\ Subjects}

Seven hundred community-dwelling men aged 40 years or above were recruited in middle and southern Japan. This convenience sample of subjects was interviewed at shopping malls or when they attended community centres or undertook health checks at hospital clinics. Subjects were excluded if they had dementia or other health conditions that prohibited them from answering the questions. A total of 668 eligible men were available for analysis after excluding participants with missing demographic details or incomplete screening tests of respiratory symptoms. No statistically significant differences were found between the included and the excluded subjects in terms of clinical and other variables. The purpose and procedure were explained to each participant before obtaining their written consent. Confidentiality 
and the right to withdraw without prejudice were ensured and maintained throughout the study. Approval of the project protocol was obtained from the Human Research Ethics Committee of the researchers' institution (approval number HR 90/2005).

\section{Questionnaires}

A structured questionnaire incorporating the International Consultation on Incontinence Questionnaire-Short Form (ICIQ-SF) [14] was administered face-to-face to assess UI status and to collect demographic information. The ICIQ-SF is a measure for evaluating the severity of urinary loss and condition-specific quality of life. The reliability, validity, and sensitivity of the instrument have been established $[14,15]$. The questionnaire consists of three components to determine frequency, quantity, and impact of urine leakage. UI was defined as a minimal amount of leakage of at least "once a week or less often", i.e. any urine leakage, during the past year. An additional question was added to the ICIQ-SF to find out how long the person had the condition.

Two screening instruments, Medical Research Council's dyspnoea scale [16] and the Australian Lung Foundation's Feeling Short of Breath scale [17], were used to assess respiratory symptoms of each individual. The latter scale consisted of five simple questions: (i) Do you cough several times most days? (ii) Do you bring up phlegm or mucous most days? (iii) Do you get out of breath more easily than others your age? (iv) Are you over 40 years old? (v) Are you smoker or ex-smoker?

Information on health conditions including hypertension, ischemic stroke, diabetes mellitus, depression and cancer was solicited from the participants. A further question on 'life-long physical activity involvement' was appended to the questionnaire, defined as "doing active sports or vigorous exercise long enough to get sweaty, at least twice a week", over the entire life course [18]. The 5-level categorical variable was dichotomized to 'not active' ("never been much involved" to "intermittently involved") and 'active' ("always been involved").

\section{Statistical analysis}

Characteristics of the two groups (with and without UI) were compared using chi-square test for categorical variables and $t$ test for continuous variables. Logistic regression analyses were then performed to estimate the prevalence of UI in relation to respiratory symptoms. Both crude and adjusted odds ratios were obtained as estimates of relative risk, the latter accounted for the effects of confounding variables namely age, body mass index (BMI), smoking, alcohol drinking status and the presence of co-morbidities.

\section{Results}

For the 668 participants, their average age was 62.7 (standard deviation (SD) 7.5; range 43 to 82 ) years and mean BMI was 23 (SD 3.1; range 14.5 to 37.8 ) $\mathrm{kg} / \mathrm{m}^{2}$. Most of the men were married (87.6\%) and 35\% of them had retired. A substantial proportion of subjects smoked (26.3\%) and consumed alcohol (70.7\%) on at least a monthly basis.

The prevalence of UI was $7.6 \%$. Table 1 presents the characteristics of subjects by UI status. The incontinent men were three years older on average and had significantly higher prevalence of respiratory symptoms than those without the condition, especially for breathlessness ( $45 \%$ versus $30 \%, p=0.025$ ). The binary breathlessness outcome was validated against the Medical Research Council's dyspnoea score. The observed spearman rank correlation of 0.7 confirmed a good agreement between the two scales. The observed dyspnoea score was also higher among the incontinent men, but the two groups were similar with respect to other co-morbidities and physical activity involvement.

Table 2 summarises the ICIQ-SF outcomes. Urine leakage among the 51 incontinent subjects was typically "a small amount" (84.3\%) and occurred once a week or less often (58.8\%). The mean ICIQ-SF total score was 6 (SD 2.7) and no one considered the condition to have interfered with their daily life to a great extent. The most common occurrence of urine loss was before reaching the toilet (number $(n)=33,64.7 \%$ ). While 30 $(58.8 \%)$ of the incontinent men experienced urge incontinence, six (11.8\%) sustained stress-type leakage, two (3.9\%) had mixed and 13 (25.5\%) reported other types. On average they had urine leakage for 2.5 (SD 1.8) years with a maximum duration of 10 years.

The proportion of men affected by UI increased from $6.4 \%$ without to $11 \%$ with breathlessness. Results of logistic regression analyses are given in Table 3, which confirmed all three respiratory symptoms were associated with increase in prevalence of UI. In particular, the adjusted odds ratio (OR) of 2.11 (95\% confidence interval (CI) 1.10-4.06) was significant for breathlessness, even after accounting for individual's age, BMI, smoking and alcohol drinking status. Moreover, none of the five health conditions were found to be significant, while the effect of breathlessness was not modified by the inclusion of these co-morbidities into the multivariate model. The correlation between the ICIQ score and the dyspnoea score was 0.24 . However, the dose-response effect of dyspnoea on UI was not significant (adjusted OR = 1.17, 95\% CI 0.90- 1.51).

\section{Discussion}

This study provides the first report of the relationship between UI and respiratory symptoms among middleaged and older men. Breathlessness was found to be associated with UI. A cross-sectional study of 7,947 community-dwelling women in the USA reported that 
Table 1 Characteristics of subjects by urinary incontinence status $(n=668$ )

\begin{tabular}{|c|c|c|c|c|}
\hline Characteristic & With UI $(n=51)$ & Without UI $(n=617)$ & $p$ & \\
\hline Age (years) & 65.4 (SD 7.2) & 62.4 (SD 7.5) & 0.007 & \\
\hline Body mass index $\left(\mathrm{kg} / \mathrm{m}^{2}\right)$ & 22.9 (SD 4.1) & $23.0($ SD 3.0) & 0.792 & \\
\hline Dyspnoea score & 1.12 (SD 1.11) & 0.84 (SD 1.12) & 0.032 & \\
\hline Breathlessness & $22(44.9 \%)$ & $178(29.6 \%)$ & 0.025 & \\
\hline Cough & $13(26.5 \%)$ & $92(15.3 \%)$ & 0.040 & \\
\hline Sputum & $18(36.7 \%)$ & $180(29.9 \%)$ & 0.317 & \\
\hline Smoking pack-years & 48.6 (SD 27.3) & 45.8 (SD 27.2) & 0.513 & \\
\hline \multirow[t]{4}{*}{ Smoking status $^{1}$} & & & 0.806 & \\
\hline & never smoker & $9(17.6 \%)$ & $100(26.0 \%)$ & \\
\hline & ex-smoker & $27(52.9 \%)$ & $352(57.6 \%)$ & \\
\hline & current smoker & $15(29.4 \%)$ & $159(16.4 \%)$ & \\
\hline \multirow[t]{3}{*}{ Alcohol drinking } & & & 0.036 & \\
\hline & yes & $30(59 \%)$ & $440(72 \%)$ & \\
\hline & no & $21(41 \%)$ & 177 (28\%) & \\
\hline \multirow[t]{3}{*}{ Marital status $^{1}$} & & & 0.124 & \\
\hline & single/divorced & $9(18 \%)$ & $68(11 \%)$ & \\
\hline & married & $42(82 \%)$ & $543(89 \%)$ & \\
\hline \multirow[t]{3}{*}{ Retirement status $^{1}$} & & & 0.092 & \\
\hline & retired & $23(45 \%)$ & $212(35 \%)$ & \\
\hline & not retired & $28(55 \%)$ & $399(65 \%)$ & \\
\hline \multirow[t]{3}{*}{ Physical activity ${ }^{1}$} & & & 0.336 & \\
\hline & not active & $40(78.4 \%)$ & $441(72.2 \%)$ & \\
\hline & active & $11(21.6 \%)$ & $170(27.8 \%)$ & \\
\hline \multicolumn{5}{|l|}{ Co-morbidities } \\
\hline & Hypertension & $7(13.7 \%)$ & $139(22.7 \%)$ & 0.137 \\
\hline & Diabetes mellitus & $7(13.7 \%)$ & $58(9.5 \%)$ & 0.372 \\
\hline & Cancer & $3(5.9 \%)$ & $22(3.6 \%)$ & 0.410 \\
\hline & Ischemic stroke & $0(0 \%)$ & 17 (2.8\%) & 0.228 \\
\hline & Depression & $0(0 \%)$ & $9(1.5 \%)$ & 0.383 \\
\hline
\end{tabular}

1 missing data present

$\mathrm{UI}$, urinary incontinence.

SD, standard deviation.

faster gait speed ( $\geq 1.04$ meter/second) was related to decreased daily UI (OR $0.8,95 \%$ CI $0.6-1.0$ ) compared with lower gait speed (<0.86 meter/second) [19]. Although walking slowly may not necessarily imply breathlessness, people who can walk fast are unlikely to suffer from breathlessness.

For women with cystic fibrosis [11] and asthma [13], stress incontinence has been related to their chronic coughing and sneezing which raise intra-abdominal pressure and cause damage to the pelvic floor [13]. Unlike women, urge-type leakage was most common among our sample of incontinent men. The observed association with breathlessness can be attributed to the continence mechanism, especially neurological control of the pelvic floor and micturation [11]. The nerve supply of the pelvic floor is via the pudendal nerve, as part of the somatic nervous system. Bladder filling and storage of urine involves autonomic control via the sympathetic system and bladder voiding is under parasympathetic control [11]. Meanwhile, breathlessness is under the sympathetic system. People who feel breathlessness are more likely to have an imbalance between sympathetic system and parasympathetic control, or may have less parasympathetic control. Once leakage occurs there is a chronic and progressive deterioration of the pelvic neuromuscular function [5].

Some limitations of the study should be considered. Classification of UI status was based on self report via the ICIQ-SF rather than objective measurements of urine loss. Despite the subjective perception of the 
Table 2 Characteristics of incontinent men $(n=51)$

\begin{tabular}{|c|c|c|c|}
\hline ICIQ item & $\mathrm{n}$ & $\%$ & \\
\hline \multicolumn{4}{|l|}{ Frequency of leakage } \\
\hline & About once a week or less often & 30 & 58.8 \\
\hline & Two or three times a week & 11 & 21.6 \\
\hline & About once a day & 4 & 7.8 \\
\hline & Several times a day & 6 & 11.8 \\
\hline & All the time & 0 & 0 \\
\hline \multicolumn{4}{|l|}{ Quantity of urine loss } \\
\hline & Nothing & 1 & 2.0 \\
\hline & A small amount & 43 & 84.3 \\
\hline & A moderate amount & 5 & 9.8 \\
\hline & A large amount & 2 & 3.9 \\
\hline \multirow[t]{5}{*}{ Interfere with everyday life } & Mean 2.0 & SD 1.9 & \\
\hline & 0 (not at all) & 15 & 29.4 \\
\hline & $1-3$ & 28 & 54.9 \\
\hline & $4-7$ & 8 & 15.7 \\
\hline & 8-10 (a great deal) & 0 & 0 \\
\hline \multicolumn{4}{|c|}{ When urine leakage occurs (multiple responses) } \\
\hline & before reaching toilet & 33 & 64.7 \\
\hline & cough or sneezing & 2 & 3.9 \\
\hline & asleep & 2 & 3.9 \\
\hline & physically active/exercising & 6 & 11.8 \\
\hline & after urinating and dressed & 10 & 19.6 \\
\hline & others & 2 & 3.9 \\
\hline ICIQ score (range 0 to 21) & Mean 6.0 & SD 2.7 & \\
\hline
\end{tabular}

$\mathrm{ICIQ}$ International Consultation on Incontinence Questionnaire.

Table 3 Respiratory symptoms and risk of urinary incontinence

\begin{tabular}{|c|c|c|c|c|c|c|c|}
\hline \multirow[t]{2}{*}{ Respiratory symptom } & \multirow{2}{*}{$\begin{array}{c}\text { Distribution } \\
\mathrm{n}(\%)\end{array}$} & \multicolumn{3}{|c|}{ Crude odds ratio } & \multicolumn{3}{|c|}{ Adjusted odds ratio ${ }^{1}$} \\
\hline & & Odds ratio & $95 \% \mathrm{Cl}$ & $p$ & Odds ratio & $95 \% \mathrm{Cl}$ & $p$ \\
\hline \multirow[t]{3}{*}{ Breathlessness } & & & & 0.027 & & & 0.025 \\
\hline & No & $455(68.1 \%)$ & 1 & & & 1 & \\
\hline & Yes & $201(30.1 \%)$ & 1.94 & $(1.08,3.50)$ & & 2.11 & $(1.10,4.06)$ \\
\hline \multirow[t]{3}{*}{ Cough } & & & & 0.043 & & & 0.137 \\
\hline & No & $551(82.5 \%)$ & 1 & & & 1 & \\
\hline & Yes & $105(15.7 \%)$ & 2.00 & $(1.02,3.92)$ & & 1.73 & $(0.84,3.54)$ \\
\hline \multirow[t]{3}{*}{ Sputum } & & & & 0.319 & & & 0.423 \\
\hline & No & $457(68.4 \%)$ & 1 & & & 1 & \\
\hline & Yes & $199(29.8 \%)$ & 1.36 & $(0.74,2.50)$ & & 1.31 & $(0.68,2.51)$ \\
\hline
\end{tabular}

${ }^{1}$ adjusted for age, BMI, smoking and alcohol drinking status in logistic regression model $\mathrm{Cl}$, confidence interval. 
condition, it is now recognised that the use of psychometrically robust self-completion questionnaires is a valid approach for assessing UI. The ICIQ-SF has good measurement properties and encompasses all aspects of incontinence $[14,15,20]$. Moreover, face-to-face interviews were conducted by the same investigator to avoid misinterpretation of the questions and to reduce interinterviewer bias. All participants resided in the community and should be representative of the underlying population. Selection bias might still exist because these voluntary participants were not randomly selected. The observed association could be confounded by the presence of co-morbid conditions. The lack of confirmation of other co-morbidities such as benign prostatic hypertrophy was another limitation of the study. Physical activity and several self-reported health conditions were not associated with urine leakage and thus unlikely to be confounders. Nevertheless, population-based prospective cohort studies are needed to confirm the apparent cause-and-effect relationship between UI and breathlessness. Experimental research to further understand the underlying biological mechanism is also important.

\section{Conclusions}

The present study has highlighted the additional burden that breathlessness can impose on middle-aged and older men. Education and regular assessment for UI are recommended, and treating respiratory symptoms should become part of the routine health management of older adults to prevent the development of this distressing condition.

\section{Author details \\ ${ }^{1}$ School of Public Health, Curtin Health Innovation Research Institute, Curtin University of Technology, Perth, WA, Australia. ${ }^{2}$ Department of Respiratory Medicine and Clinical Immunology, Toyota Kosei Hospital, Aichi Prefectural Welfare Federation of Agricultural Cooperatives, Aichi, Japan. ${ }^{3}$ Department of Respiratory Medicine and Allergy, Komaki City Hospital, Aichi, Japan. \\ Authors' contributions \\ $\mathrm{FH}$ collected the data and drafted the manuscript. AHL analysed the data and revised the manuscript. $\mathrm{TH}$ and $\mathrm{YT}$ assisted with data collection and interpretation of the findings. All authors read and approved the final version of the paper.}

\section{Competing interests}

The authors declare that they have no competing interests.

Received: 8 April 2009

Accepted: 6 January 2010 Published: 6 January 2010

\section{References}

1. Hunskaar S, Burgio K, Diokno AC, Herzog AC, Hjälmaás K, Lapitan MC, Eds: Incontinence: Second International Consultation on Incontinence Paris, July 1-3, 2001. Plymouth: Health Publication LtdAbrams P, Cardozo L, Khoury S, Wein A , 2 2002, 182-191.

2. Dallosso HM, McGrother CW, Matthews RJ, Donaldson MM: The association of diet and other lifestyle factors with overactive bladder and stress incontinence: a longitudinal study in women. BJU Int 2003, 92:69-77.
3. Danforth KN, Townsend MK, Lifford K, Curhan GC, Resnick NM, Grodstein F: Risk factors for urinary incontinence among middle-aged women. Am J Obstet Gynecol 2006, 194:339-345.

4. Yoshimura K, Kamoto T, Tsukamoto T, Oshiro K, Kinukawa N, Ogawa O: Seasonal alterations in nocturia and other storage symptoms in three Japanese communities. Urology 2007, 69:864-870.

5. Orr A, McVean RJ, Webb AK, Dodd ME: Questionnaire survey of urinary incontinence in women with cystic fibrosis. BMJ 2001, 322:1521.

6. Cornacchia M, Zenorini A, Perobelli S, Zanolla L, Mastella G, Braggion C: Prevalence of urinary incontinence in women with cystic fibrosis. $B J U$ Int 2001, 88:44-48

7. Moran F, Bradley JM, Boyle L, Elborn JS: Incontinence in adult females with cystic fibrosis: a Northern Ireland survey. Int J Clin Pract 2003, 57:182-183.

8. Barry MJ, Link CL, MCNaughton-Collins MF, McKinlay JB: Overlap of different urological symptom complexes in a racially and ethnically diverse, community-based population of men and women. BJU Int 2008, 101:45-51.

9. Jackson RA, Vittinghoff E, Kanaya AM, Miles TP, Resnick HE, Kritchevsky SB, Simonsick EM, Brown JS: Urinary incontinence in elderly women: findings from the Health, Aging, and Body Composition Study. Obstet Gynecol 2004, 104:301-307.

10. Kocak I, Okyay P, Dundar M, Erol H, Beser E: Female urinary incontinence in the west of Turkey: prevalence, risk factors and impact on quality of life. Eur Urol 2005, 48:634-641.

11. Dodd ME, Langman $\mathrm{H}$ : Urinary incontinence in cystic fibrosis. $J R$ Soc Med 2005, 98(Suppl 45):28-36.

12. Neumann PB, Grimmer KA, Deenadayalan Y: Pelvic floor muscle training and adjunctive therapies for the treatment of stress urinary incontinence in women: a systematic review. BMC Womens Health 2006, 6:1-28.

13. Tennstedt $\mathrm{SL}$, Link $\mathrm{CL}$, Steers WD, McKinlay JB: Prevalence of and risk factors for urine leakage in a racially and ethnically diverse population of adults: the Boston Area Community Health (BACH) Survey. Am J Epidemiol 2008, 167:390-399.

14. Avery K, Donovan J, Peters TJ, Shaw C, Gotoh M, Abrams P: ICIQ: a brief and robust measure for evaluating the symptoms and impact of urinary incontinence. Neurourol Urodyn 2004, 23:322-330.

15. Karantanis E, Fynes M, Moore KH, Stanton SL: Comparison of the ICIQ-SF and 24-hour pad test with other measures for evaluating the severity of urodynamic stress incontinence. Int Urogynecol J Pelvic Floor Dysfunct 2004, 15:111-116.

16. Bestall JC, Paul EA, Garrod R, Garnham R, Jones PW, Wedzicha JA: Usefulness of the Medical Research Council (MRC) dyspnoea scale as a measure of disability in patients with chronic obstructive pulmonary disease. Thorax 1999, 54:581-586.

17. Managament tools. http://www.copdx.org.au/checklist/index.asp.

18. O' Brien Cousins S, Tan M: Sources of efficacy for walking and climbing stairs among older adults. Phys Occup Ther Geriatr 2002, 20:51-68.

19. Brown JS, Seeley DG, Fong J, Black DM, Ensrud KE, Grady D: Urinary incontinence in older women: who is at risk? Study of Osteoporotic Fractures Research Group. Obstet Gynecol 1996, 87:715-721.

20. Avery KN, Bosch JL, Gotoh M, Naughton M, Jackson S, Radley SC, Valiquette L, Batista J, Donovan JL: Questionnaires to assess urinary and anal incontinence: review and recommendations. J Urol 2007, 177:39-49.

Pre-publication history

The pre-publication history for this paper can be accessed here:http://www. biomedcentral.com/1471-2466/10/2/prepub

\section{doi:10.1186/1471-2466-10-2}

Cite this article as: Hirayama et al:: Breathlessness is associated with urinary incontinence in men: A community-based study. BMC Pulmonary Medicine 2010 10:2. 